Research article

\title{
Assessment of health benefits related to air quality improvement strategies in urban areas: An Impact Pathway Approach
}

\author{
Carlos Silveira ${ }^{\mathrm{a},{ }^{*}, \text { Peter Roebeling a }}{ }^{\text {, Myriam Lopes }}{ }^{\mathrm{a}}$, Joana Ferreira ${ }^{\mathrm{a}}$, Solange Costa ${ }^{\mathrm{b}, \mathrm{c}}$, \\ João P. Teixeira ${ }^{\mathrm{b}, \mathrm{c}}$, Carlos Borrego ${ }^{\mathrm{a}}$, Ana I. Miranda ${ }^{\mathrm{a}}$ \\ a CESAM, Department of Environment and Planning, University of Aveiro, 3810-193 Aveiro, Portugal \\ ${ }^{\mathrm{b}}$ EPIUnit, Institute of Public Health, University of Porto, 4050-600 Porto, Portugal \\ ${ }^{\mathrm{c}}$ National Institute of Health, Environmental Health Department, 4000-055 Porto, Portugal
}

\section{A R T I C L E I N F O}

\section{Article history:}

Received 13 November 2015

Received in revised form

9 May 2016

Accepted 30 August 2016

Available online 15 September 2016

\section{Keywords:}

Air pollution

Emission abatement measures

Air quality improvement

Health impacts

Avoided external costs

\begin{abstract}
A B S T R A C T
Air pollution is, increasingly, a concern to our society given the threats to human health and the environment. Concerted actions to improve air quality have been taken at different levels, such as through the development of Air Quality Plans (AQPs). However, air quality impacts associated with the implementation of abatement measures included in AQPs are often neglected. In order to identify the major gaps and strengths in current knowledge, a literature review has been performed on existing methodologies to estimate air pollution-related health impacts and subsequent external costs. Based on this review, the Impact Pathway Approach was adopted and applied within the context of the MAPLIA research project to assess the health impacts and benefits (or avoided external costs) derived from improvements in air quality. Seven emission abatement scenarios, based on individual and combined abatement measures, were tested for the major activity sectors (traffic, residential and industrial combustion and production processes) of a Portuguese urban area (Grande Porto) with severe particular matter (PM10) air pollution problems. Results revealed a strong positive correlation between population density and health benefits obtained from the assessed reduction scenarios. As a consequence, potential health benefits from reduction scenarios are largest in densely populated areas with high anthropic activity and, thus, where air pollution problems are most alarming. Implementation of all measures resulted in a reduction in PM10 emissions by almost $8 \%$, improving air quality by about $1 \%$ and contributing to a benefit of 8.8 million $€ /$ year for the entire study domain. The introduction of PM10 reduction technologies in industrial units was the most beneficial abatement measure. This study intends to contribute to policy support for decision-making on air quality management.
\end{abstract}

(C) 2016 Elsevier Ltd. All rights reserved.

\section{Introduction}

Air pollution is a worldwide problem with widely known harmful effects to human health and the environment. To reverse or minimize this trend, multiple joint efforts involving government entities, organizations and citizens have been made. The strategy to reduce these negative effects, particularly in cities where the majority of the world population lives, it is to define air quality improvement policies. In this sense, European Union Member States are obligated to establish Air Quality Plans (AQPs) for their

\footnotetext{
* Corresponding author.

E-mail address: carlos.silveira@ua.pt (C. Silveira).

URL: http://www.cesam.ua.pt
}

zones/agglomerations in accordance with the Air Quality Directive (AQD; EC, 2008) whenever exceedances of air quality limit values are recorded. Unfortunately, aspects beyond air quality are not addressed or quantified in the vast majority of these plans. When air quality impacts are analysed, the great research challenge lies in quantifying the intensity of the adverse effects as well as the associated costs (DEFRA, 2004). These costs are known as negative externalities, involving external costs to repair a given reference situation or avoid welfare losses. A comprehensive economic analysis starts with a clear identification of the involved air pollutants and their effects on different damage categories, including health impacts, building and material damages, crop and biodiversity losses, and ecosystem degradation (van Essen et al., 2011). Among these damage categories, health impacts caused by air pollution contribute to the largest part of the external cost 
estimates. This finding is shared by public health experts that link air pollution, even at current ambient levels, to worsened morbidity (especially respiratory and cardiovascular diseases) and premature mortality (e.g. years of lost life) (EC, 2005). Underlying these issues, a large variety of environmental factors must be previously analysed, such as overall pollution levels, characterization of emission sources (e.g. relative contribution by activity sector, geographic location and height of release points), population structure (e.g. density and spatial distribution, age groups) and the meteorological conditions influencing transport, dispersion and chemistry of air pollutants (e.g. Holland et al., 2005).

The definition of air quality management strategies can be aided by effectiveness, cost-effectiveness and cost-benefit assessments of emission reduction scenarios (e.g. Carnevale et al., 2012). Effectiveness studies assess the extent to which these scenarios result in emission reductions and associated air quality improvements. Costeffectiveness studies assess, in addition, the monetary costs associated with the implementation of these scenarios and, hence, facilitate the identification of those scenarios that achieve emission reductions and/or air quality improvements at least cost. Finally, cost-benefit studies assess, moreover, the monetary benefits associated with air quality improvements and, therefore, facilitate the identification of those scenarios that provide largest welfare gains. Monetary costs associated with the implementation of emission reduction measures and scenarios are, generally, estimated on the basis of measure implementation rates and corresponding unit costs (e.g. following the GAINS methodology; IIASA, 2012). The estimation of the monetary benefits from emission reduction measures and scenarios is, however, more complex given the multiple, interacting and uncertain exposure/dose-response relationships as well as economic valuation issues (see Silveira et al., 2015).

This paper presents a review on the available methodologies for the quantification of air pollution-related health impacts and subsequent external costs as to, in turn, assess emission reduction scenarios designed in the research project MAPLIA (http://projetomaplia.web.ua.pt/). To achieve this goal, the following specific objectives are established: i) identify the relevant physical health impacts and establish exposure-response functions that allow to calculate the number of attributable cases; ii) identify the different cost components related to the impacts and estimate their monetary value; and iii) use these data to assess health impacts and benefits from the implementation of emission abatement measures/scenarios in a Portuguese urban area (Grande Porto). These measures are focused on the major sources of PM10 - the air pollutant that recorded exceedances from air quality limit values established in the AQD. Finally, weaknesses and recommendations regarding the economic evaluation of air pollution impacts on human health are discussed.

\section{Health impacts of air pollution}

This section presents a summary description of the methodological assumptions underlying the quantification of air pollutionrelated health impacts (Section 2.1) and subsequent economic evaluation of corresponding damages (Section 2.2). Thereafter, an overview of research studies underpinning these methodologies is presented (Section 2.3), in particular with respect to the key impact functions and associated external costs.

\subsection{Physical health impacts}

Physical health impacts caused by exposure to air pollutants are expressed through morbidity and mortality indicators, related with respiratory and cardiovascular diseases. Regarding the most common air pollutants (particulate matter, ozone, sulphur dioxide and nitrogen oxides), the following health effects are frequently reported: i) reduction in life expectancy due to acute and chronic mortality; ii) chronic effects on morbidity, such as bronchitis and cough in children and asthmatics; and iii) acute effects on morbidity, namely respiratory and cardiovascular hospital admissions, asthma episodes and restricted activity. This implies three different types of cause-effect relationships, that are strongest for particulate matter (PM) as compared to other air pollutants (EHA, 2006; Pervin et al., 2008) and, thus, their effects are better documented and quantified (e.g. Mechler et al., 2002; Ruckerl et al., 2011).

The quantification of these health impacts is based on the correlation between exposure and effect, depending on the specificity and availability of data and models (Holland et al., 2005). Often, due to unavailability/lack of epidemiological studies based on country data, exposure-response functions (ERFs) are taken from international epidemiological studies that are regarded as reference studies by the scientific community. In this context, ERFs based on relative risk models have been applied to translate air concentrations into health impacts. Numerous studies show that certain vulnerable groups within a population (e.g. elderly people, children and those with underlying diseases) have a greater risk of being affected by air pollutants (Costa et al., 2014; Pervin et al., 2008; WHO, 2013a).

These ERFs may be linear or non-linear and, either or not, contain threshold exposure values. Nevertheless, the vast majority of the available methodologies assumes that the cause-effect relation is linear, in the form of a Poisson regression, which usually does not reflect the real situation as there is a threshold exposure value below which the physical impact is no longer felt. Therefore, these approaches are considered more appropriate for situations in which the increase in pollutant emissions is marginal and when the supposed linearity is not violated and, hence, the applicability domain (i.e. exposure concentration range) of the model should be clearly stated (Marques et al., 2013; Pizzol et al., 2010).

Adverse health effects occur often within a short time after exposure (short-term exposure), resulting in acute effects. Nevertheless, it is important to also consider the cumulative exposure over time (long-term exposure) that result in chronic effects (Costa et al., 2014). Short-term exposure studies usually explore timeseries of hourly and daily changes in air pollution, and daily death counts or cause-specific hospitalizations (Ruckerl et al., 2011). Long-term exposure studies assess the increase in mortality risk due to chronic exposure to air pollution (Seethaler et al., 2003; WHO, 2013a). To design the overall effect of air pollution on life expectancy, cohort studies have been used to provide results in terms of changes in mortality risk (age-specific death rates) per unit change in pollutant concentration. For impact estimation, this change in mortality risk can be most reliably represented using life table methods to express mortality impacts in the target population, translated in terms of life expectancy changes and/or in total life-years gained or lost for a given air pollution scenario (Hurley et al., 2005a).

\subsection{Economic evaluation of impacts}

The economic valuation of health impacts arising from air pollution is, generally, based on the cost-of-illness (COI) approach (see Pervin et al., 2008; WHO, 2008). According to the COI approach, total health costs $\left(C_{\text {health }}\right)$ are determined by the sum of direct $\left(C_{\text {direct }}\right)$, indirect $\left(C_{\text {indirect }}\right)$ and intangible $\left(C_{\text {intangible }}\right)$ costs (Pervin et al., 2008): 
$C_{\text {health }}=C_{\text {direct }}+C_{\text {indirect }}+C_{\text {intangible }}$

Direct costs include health care and non-health care costs associated with treatment and caring. These costs are based on market values for e.g. medical staff, examinations, laboratory tests, medication, consumables and hospital facilities as well as for caregivers' time, and are estimated using bottom-up or top-down accounting methods (Pervin et al., 2008).

Indirect costs include costs associated with loss of productivity due to morbidity as well loss of production due to morbidity or mortality. These costs are based on market values for e.g. wages, incomes and earnings, and are estimated using the human capital approach (HCA) or the friction cost approach (FCA) (Hanly et al., 2012; Pervin et al., 2008). The HCA approach assesses an individual's productivity and production losses from health deterioration, based on the time foregone from productive activities over the individual's lifetime and against the relevant wage rate (Tranmer et al., 2005). The FCA approach assesses a firm's productivity and production losses from health deterioration, based on the time needed to restore initial production levels (friction period) and assuming vacancies are filled by unemployed (low opportunity cost) employees (Koopmanschap and van Ineveld, 1992).

Finally, intangible costs include non-market costs associated with pain and suffering. These costs are based on non-market values for pain and suffering from morbidity and mortality, and are estimated using quality-adjusted-life-year (QALY) and willingness-to-pay (WTP) or willingness-to-accept (WTA) approaches (Hammitt, 2007). The QALY approach assesses the change in QALYs, and corresponding monetary values, due to an expected change in health (Pizzol et al., 2014). Estimates are invariably dependent on life expectancy, future health and latency, though rarely dependent on income or risk characteristics (Hammitt, 2007). The "willingness-to" approaches assess an individual's willingness to spend money for an expected health improvement (WTP; compensating variation) or, alternatively, an individual's willingness to receive money to forgo an expected health improvement (WTA; equivalent variation). Estimated values may be a function of income, education and age as well as environmental quality (Hammitt, 2007; Seethaler et al., 2003).

\subsection{Overview of the research studies}

This section compiles scientific/technical information for different health indicators (i.e. extent of health effects) associated with air pollution. For the reasons outlined in Section 2.1, only health effects associated with particulate matter (PM2.5 and PM10) are presented (Table 1). Note, however, that health effects caused by other air pollutants (e.g. ozone and nitrogen oxides) should not be overlooked when the goal is to make a comprehensive health impact assessment. For each health indicator the following aspects are considered: affected age groups, exposure time, impact functions (as relative risk) and damage costs per unit.

Largest relative risk impacts from PM air pollution are associated with cough, asthma, cardiovascular hospital admissions, as well as cardiopulmonary mortality. External costs due to morbidity are largest for bronchitis, congestive heart failure and respiratory and cardiovascular hospital admissions. In relation to mortality costs, they vary between 21 and 77 thousand Euro per case for adults over 30 years of age. Hence, it is expected that largest external costs from PM air pollution are associated with cardiovascular health problems.

For certain health indicators the pollutant effect on a given age group reveals considerable variation in terms of exposure-response functions (i.e. ERFs) and external costs, which can be explained by the differing methodologies, the geographical coverage and socioeconomic conditions across studies. The research studies reported in Table 1 are designed for Europe as a whole (e.g. Brandt et al., 2013; WHO, 2013b), while some studies are country specific (e.g DEFRA, 2013; Seethaler, 1999).

The variability in ERFs may be associated with several factors, namely the population structure (density, affected age groups and their distribution), source of data gathering, and unavailability or improper format of routinely gathered health indicator data for use in economic evaluations. In addition, the inclusion/exclusion of threshold exposure values as well as cumulative effects over time have contributed to the variation in derived risk functions (Hurley et al., 2005a).

The variability in external cost estimates is particularly large when these build on WTP studies. WTP studies are based on interviews in which personal interpretation of the questions as well as strategic behaviour by respondents can lead to biased outcomes (Pervin et al., 2008). Furthermore, these values might also depend on additional variables, such as income and age and, probably, differ between health effects (WHO, 2008). The WTP approach has the advantage of acquiring the full range of personal costs associated with the disease (Pervin et al., 2008), thereby noting that many of those costs have no market value (Belhaj and Fridell, 2010). As a consequence, several health effects due to air pollution are often neglected and, hence, results are probably an underestimation of the total health costs (WHO, 2008).

\section{Methodology}

The approach adopted for assessing the impacts of atmospheric emissions on human health is described in Section 3.1. Its application is demonstrated in Section 3.2, where different emission abatement measures/scenarios are evaluated for the case of PM10 air pollution in a Portuguese urban area (Grande Porto).

\subsection{Impact Pathway Approach}

The air pollution impact chain is analysed by relating atmospheric emissions from the main activity sectors to air quality state, associated physical impacts and, finally, the monetary value of this impact (Fig. 1). In this sense, the Impact Pathway Approach (IPA), designed within the ExternE (External Costs of Energy) project (EC, 2005), is often used by the scientific community to obtain damage estimates for different impact categories. Moreover, this approach allows for the benefit analysis of policy options for air quality management - understanding avoided external costs as benefits from air quality improvement (Holland et al., 2005). Miranda et al. (2015) reviewed the assessment capabilities and modelling tools used in the development of European air quality plans to evaluate the effects of emission abatement strategies.

The health impacts arising from air pollution can be estimated using the Costa et al. (2014) study that describes how health can be integrated in air quality assessments through exposure and doseresponse functions. Thereby, emphasis will be given to the following components: physical impacts that consider different health indicators, and external costs to remediate damages or prevent productivity losses, pain and suffering. To quantify the extent of these impacts, the IPA has been applied from a bottom-up perspective. This methodology requires epidemiological information on exposure-response functions (effect estimates) and health outcome frequencies (mortality and morbidity, prevalence, incidence or person-days) which, combined with the population exposure to air pollution, provides the number of attributable cases/days: 
Table 1

Epidemiological data and economic evaluation of health effects related to PM2.5 and PM10.

\begin{tabular}{|c|c|c|c|c|c|c|}
\hline \multirow[t]{2}{*}{ Health effect (pollutant) } & \multirow[t]{2}{*}{ Age group } & \multirow[t]{2}{*}{ Study design } & \multirow[t]{2}{*}{ Relative risk (95\% CI) } & \multicolumn{2}{|c|}{$\begin{array}{l}\text { External costs (prices per } \\
\text { unit) }\end{array}$} & \multirow[t]{2}{*}{ Reference } \\
\hline & & & & $€$ (base year) & Unit & \\
\hline \multicolumn{7}{|l|}{ Morbidity } \\
\hline \multirow[t]{4}{*}{ Cough (PM2.5) } & Children & & 0.22 & & & Hurley et al. (2005a) \\
\hline & Adults & & 0.28 & & & Hurley et al. (2005a) \\
\hline & Children $<16$ yr & & 0.45 & $59(2006)$ & Day & Brandt et al. (2013) \\
\hline & Adults $>15 y r$ & & 0.28 & $59(2006)$ & Day & Brandt et al. (2013) \\
\hline \multirow[t]{2}{*}{ Cough (PM10) } & Children & & 0.13 & & & Hurley et al. (2005a) \\
\hline & Adults & & 0.17 & & & Hurley et al. (2005a) \\
\hline Chronic cough (PM2.5) & Children & Long-term & $3.46 \mathrm{E}-03$ & & & Hurley et al. (2005a) \\
\hline Chronic cough (PM10) & Children & Long-term & 2.07E-03 & & & Hurley et al. (2005a) \\
\hline \multirow[t]{5}{*}{ Asthma (PM10) } & Children 5-19 yr & Short-term & $0.28(0.06-0.51)$ & & & WHO (2013b) \\
\hline & Children $<15$ yr & & $0.44(0.27-0.62)$ & & & Seethaler (1999) \\
\hline & Adults $\geq 15 \mathrm{yr}$ & & $0.39(0.19-0.59)$ & & & Seethaler (1999) \\
\hline & & & & 31 & Day & Seethaler et al. (2003) \\
\hline & & & & $85(2000)$ & Day & Belhaj and Fridell (2010) \\
\hline Acute bronchitis (PM10) & Children & Short-term & & 131 & Day & Seethaler et al. (2003) \\
\hline \multirow[t]{2}{*}{ Bronchitis (PM10) } & Children $<15 \mathrm{yr}$ & & $3.06(1.35-5.02)$ & & & Seethaler (1999) \\
\hline & Children 6-18 yr & Long-term & $0.8(0-1.9)$ & & & WHO (2013b) \\
\hline \multirow[t]{2}{*}{ Chronic bronchitis (PM2.5) } & Adults & Long-term & $3.90 \mathrm{E}-05$ & & & Hurley et al. (2005a) \\
\hline & Adults & & $8.20 \mathrm{E}-0.5$ & $52,962(2006)$ & Case & Brandt et al. (2013) \\
\hline \multirow[t]{2}{*}{ Chronic bronchitis (PM10) } & Adults & & $2.45 \mathrm{E}-0.5$ & & & Hurley et al. (2005a) \\
\hline & Adults $>18 \mathrm{yr}$ & Long-term & $1.17(0.40-1.89)$ & & & WHO (2013b) \\
\hline Chronic bronchitis incidence (PM10) & Adults $>27 \mathrm{yr}$ & & $0.98(0.09-1.94)$ & & & Seethaler (1999) \\
\hline & Adults $>27 \mathrm{yr}$ & & $2.65 \mathrm{E}-0.5$ & $153,000(2002)$ & Case & Maibach et al. (2008) \\
\hline & Adults & & & $168,840(2000)$ & Case & Belhaj and Fridell (2010) \\
\hline & & & & 209,000 & Case & Seethaler et al. (2003) \\
\hline & & & & 190,000 & Case & Holland et al. (2005) \\
\hline Congestive heart failure (PM2.5) & Over 65 & & 3.09E-05 & & & Hurley et al. (2005a) \\
\hline & & & 3.09E-05 & $16,409(2006)$ & Case & Brandt et al. (2013) \\
\hline Congestive heart failure (PM10) & Over 65 & & $1.85 \mathrm{E}-05$ & & & Hurley et al. (2005a) \\
\hline & Over 65 & & & $3360(2000)$ & Case & Belhaj and Fridell (2010) \\
\hline Respiratory HA (PM2.5) & All ages & & $3.46 \mathrm{E}-06$ & & & Hurley et al. (2005a) \\
\hline & All ages & Short-term & $0.19(0-0.40)$ & & & WHO (2013b) \\
\hline & & & $3.46 \mathrm{E}-06$ & $7931(2006)$ & Case & Brandt et al. (2013) \\
\hline Respiratory HA (PM10) & All ages & & 2.07E-06 & & & Hurley et al. (2005a) \\
\hline & All ages & & 7.03E-03 & $1900(2002)$ & Case & Maibach et al. (2008) \\
\hline & All ages & & $0.13(0.01-0.25)$ & & & Seethaler (1999) \\
\hline & & Short-term & 0.08 & $3313-13,633$ (2012) & Case & DEFRA (2013) \\
\hline Respiratory HA & All ages & & & $4400(2000)$ & Case & Belhaj and Fridell (2010) \\
\hline & & & & $1604(2003)$ & Case & DEFRA (2004) \\
\hline Cardiovascular HA (PM2.5) & All ages & Short-term & $0.091(0.017-0.166)$ & & & WHO (2013b) \\
\hline Cardiovascular HA (PM10) & All ages & & $4.34 \mathrm{E}-06$ & $1900(2002)$ & Case & Maibach et al. (2008) \\
\hline & All ages & & $0.13(0.07-0.19)$ & & & Seethaler (1999) \\
\hline & All ages & Short-term & 0.08 & $3822-12,614(2012)$ & Case & DEFRA (2013) \\
\hline & All ages & Short-term & $0.06(0.03-0.09)$ & & & Hurley et al. (2005a) \\
\hline & All ages & Short-term & $0.09(0.04-0.15)$ & & & Ballester et al. (2006) \\
\hline Cardiovascular HA & & & & $5106(2003)$ & Case & DEFRA (2004) \\
\hline Mortality & & & & & & \\
\hline Lung cancer (PM2.5) & & & $1.3(0.4-2.2)$ & & Case & Mechler et al. (2002) \\
\hline & & & $1.26 \mathrm{E}-05$ & $21,152(2006)$ & Case & Brandt et al. (2013) \\
\hline Respiratory mortality (PM10) & All ages & Short-term & $0.13(0.05-2.0)$ & & & WHO (2008) \\
\hline Cardiopulmonary mortality (PM2.5) & Adults $>30 \mathrm{yr}$ & Long-term & $0.8(0.2-1.4)$ & & Case & Mechler et al. (2002); WHO (2008) \\
\hline Cardiovascular mortality (PM10) & All ages & Short-term & $0.09(0.05-1.3)$ & & & WHO (2008) \\
\hline Acute mortality (PM2.5) & & & 0.068 & & & Hurley et al. (2005a) \\
\hline Acute mortality (PM10) & & & 0.04 & & & Hurley et al. (2005a) \\
\hline Chronic mortality (PM2.5) & Adults $>30 \mathrm{yr}$ & & $1.138 \mathrm{E}-0.3$ & $77,199(2006)$ & YOLL & Brandt et al. (2013) \\
\hline Chronic mortality (PM10) & All ages & & $4.00 \mathrm{E}-04$ & $40,300(2002)$ & Case & Maibach et al. (2008) \\
\hline & & & & $44,595(2012)$ & Case & DEFRA (2013) \\
\hline Total mortality - All causes (PM2.5) & Age $>9$ months & & $6.68 \mathrm{E}-06$ & $3,167,832(2006)$ & Case & Brandt et al. (2013) \\
\hline & Adults $>30 \mathrm{yr}$ & Long-term & $0.6(0.2-1.0)$ & 63,447 & Case & Mechler et al. (2002); WHO (2008) \\
\hline & Adults $>30 \mathrm{yr}$ & Long-term & $0.62(0.40-0.83)$ & & & WHO (2013b) \\
\hline Total mortality - All causes (PM10) & Age $<1 \mathrm{yr}$ & Long-term & $0.4(0.2-0.7)$ & & & WHO (2013b); WHO (2008) \\
\hline & Adults $>30 \mathrm{yr}$ & & $0.43(0.26-0.61)$ & & & Seethaler (1999); WHO (2008) \\
\hline & All ages & Short-term & $0.123(0.045-0.201)$ & & & WHO (2013b) \\
\hline
\end{tabular}

Notes:

- Relative risk per $\mu \mathrm{g} \mathrm{m}^{-3} /$ person.

- Brandt et al. (2013), Hurley et al. (2005a), Maibach et al. (2008) used the ExternE impact functions (baseline annual rate included in RR).

For long-term studies annual mean concentrations are often used; for short-term studies daily PM means are used.

- HA = Hospital admissions; YOLL = Years of life lost. 


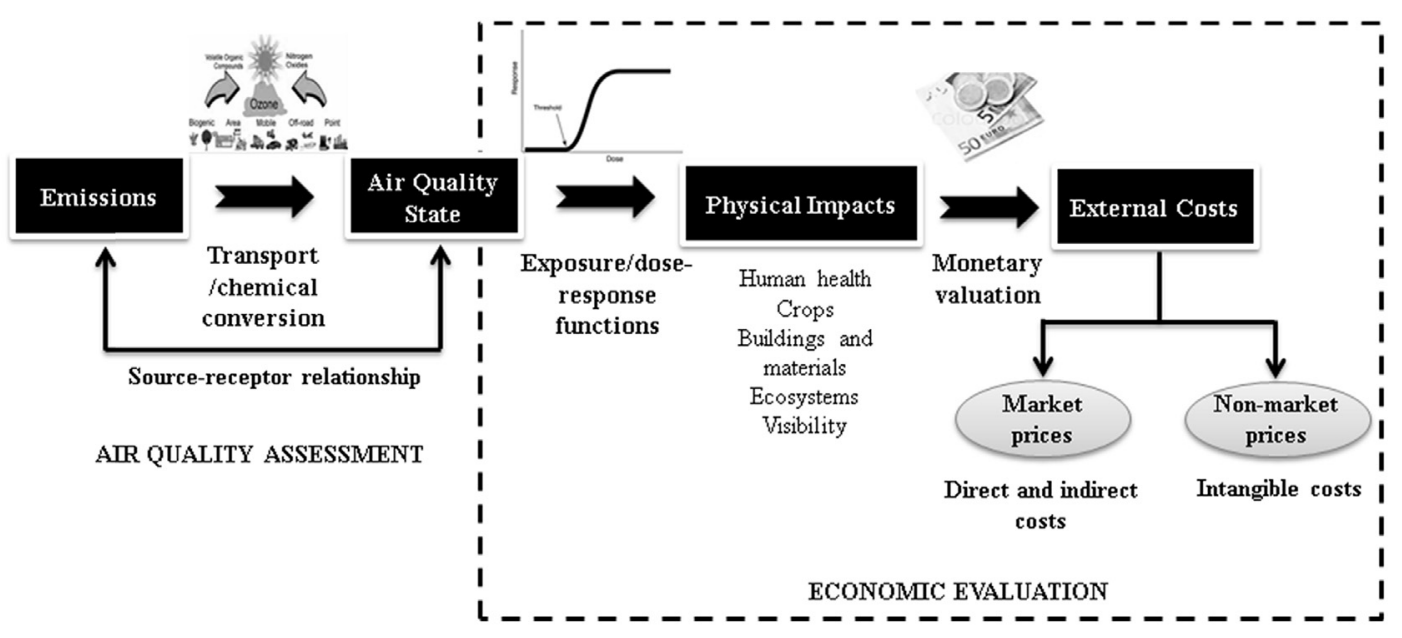

Fig. 1. Different stages leading to the evaluation of emission impacts. (source: Silveira et al., 2015).

$\Delta \mathrm{R}_{\mathrm{i}}=\mathrm{I}_{\mathrm{ref}} \times \mathrm{CRF}_{\mathrm{i}, \mathrm{p}} \times \Delta \mathrm{C}_{\mathrm{p}} \times \mathrm{pop}$

where $\Delta R_{i}$ is the response as a function of the number of the unfavorable implications (cases, days or episodes) over all health indicators $(i=1, \ldots, n)$ avoided or not, $I_{\text {ref }}$ is the baseline morbidity/ mortality annual rate, $C R F_{i, p}$ is the correlation coefficient between the pollutant $p$ 's concentration variation and the probability of experiencing or avoiding a specific health indicator $i$ (i.e. relative risk), $\Delta C_{p}$ is the change in the pollutant p's concentration, and where pop are the population units per age group exposed to pollutant $p$.

The concentration of air pollutants and population data are combined to estimate human exposure and, in turn, the impact coefficient $\left(C R F_{i, p}\right)$ is calculated using an ERF expressed as relative risk (RR) derived from epidemiological studies. Note that in some cases the baseline morbidity/mortality rate $\left(I_{\text {ref }}\right)$ is incorporated in the CRF (e.g. Brandt et al., 2013; EC, 2005; Wang and Mauzerall, 2006). The resulting physical impacts are translated into monetary values (i.e. external costs), including direct costs, indirect costs and intangible costs (see Section 2.2; Pervin et al., 2008; Seethaler et al., 2003).

Emission and air pollution abatement benefit functions are derived by plotting emission/pollution reductions against corresponding external benefits (i.e. avoided external costs), and estimating corresponding functions using ordinary least squares techniques (following Roebeling et al., 2009). Emission abatement benefits $(E A B$; in million $€ /$ year) and air pollution abatement benefits $(P A B$; in million $€ /$ year) are estimated by:

$E A B=\alpha_{1} E A$

$P A B=\alpha_{2} P A$

where $E A$ is the emission abatement (\% decrease as compared to current emissions), $P A$ is the air pollution abatement (\% decrease as compared to current air pollution), $\alpha_{1}$ is the monetary health benefit from a one percent reduction in emissions, and $\alpha_{2}$ is the monetary health benefit from a one percent reduction in air pollution.

\subsection{Application to a Portuguese urban area}

The IPA was applied with high spatial resolution to quantify health impacts/benefits from air quality improvement scenarios due to short for long-term air pollution exposure. The Grande Porto urban area and neighboring municipalities, located in the northwest of Portugal (Fig. 2), was selected due to occurrence of air pollution problems recorded throughout 2012 - in particular PM10 exceedances from air quality limit values established in the AQD (EC, 2008).

In order to reduce air pollution levels in the study domain, mainly of PM10, the following emission abatement measures that are focused on the major activity sectors were analysed along the impact chain:

1) Replacing $10 \%$ of light vehicles below Euro 3 by hybrid vehicles (HYB);

2) Replacing/reconverting $50 \%$ of fireplaces (FIR);

3) Introducing a Low Emission Zone in the city of Porto that bans the movement of vehicles below Euro 3 (Fig. 2) (LEZ); and

4) Implementation of particle emission reduction technologies allowing to reduce $10 \%$ of PM10 emissions arising from industrial combustion and production processes (IND).

These measures were considered individually and combined, resulting in 15 emission abatement measures/scenarios that are assessed with respect to their expected health impacts and benefits. For each abatement measure/scenario the base year emissions (2012; reference scenario) were recalculated by SNAP (Selected Nomenclature for Air Pollution) sector according to the measure type, using preferentially bottom-up approaches. Resulting emissions were used as input data for the TAPM (The Air Pollution Model; Hurley et al., 2005b), in order to assess the air quality improvements based on the reference scenario. The TAPM was applied with a $1-\mathrm{km}^{2}$ spatial resolution and 1-h temporal resolution, and the modelling results were validated against measured data from air quality monitoring stations, such as Borrego et al (2012) made over several Portuguese areas.

Based on the achieved air quality state for the different abatement measures/scenarios, the human health impacts were quantified using Equation (2). These impacts were analysed through morbidity and mortality indicators associated with short and longterm exposure to PM10 concentrations. For each health indicator a survey of the associated external costs per case/day was carried out Note that the long-term exposure costs were expressed as annual average costs, taking into account the duration and chronic effects 


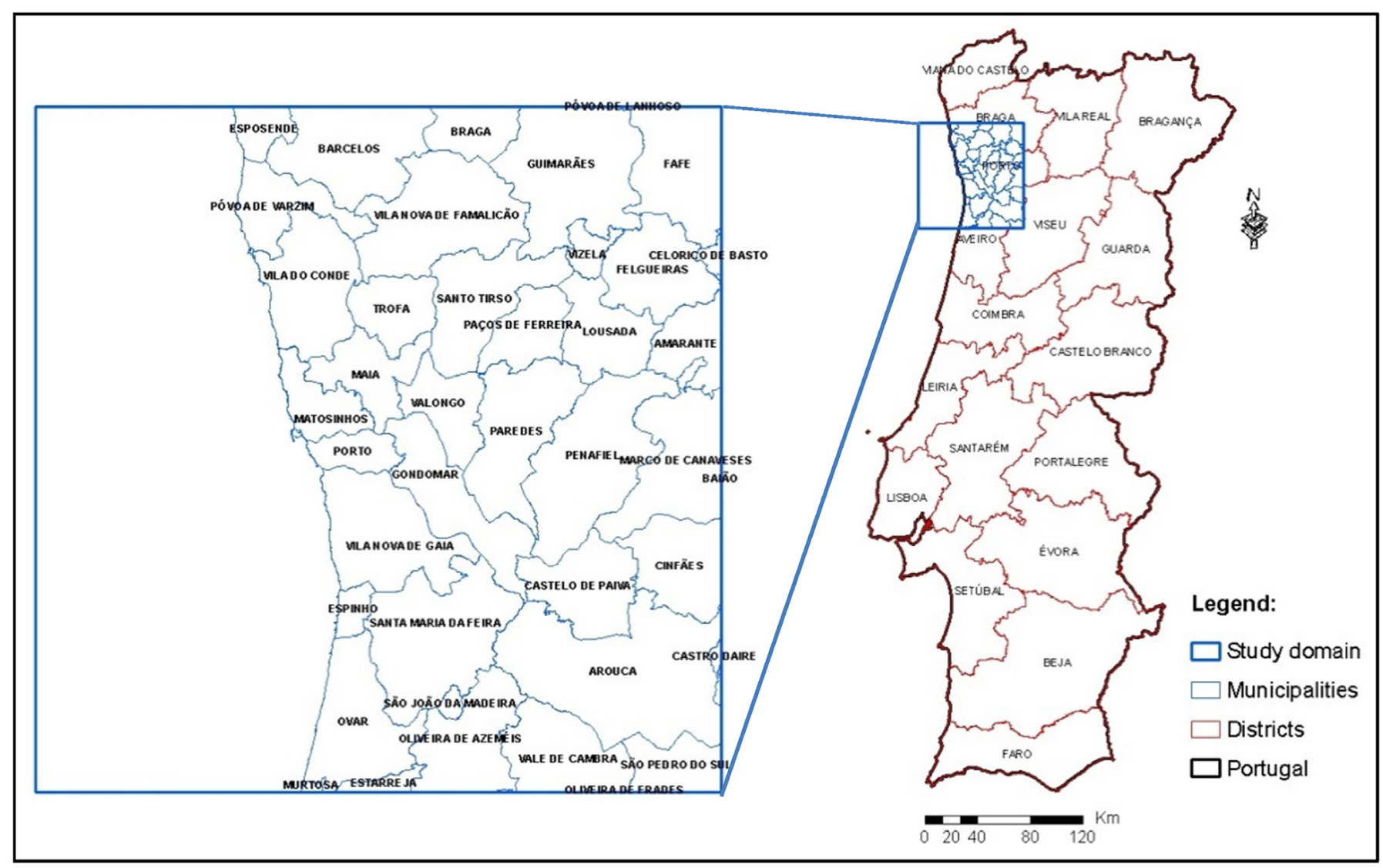

Fig. 2. Geographic location of the study domain.

of the disease. Table 2 summarizes the information used to estimate health impacts (ERFs recommended in WHO, 2013b) and subsequent external costs (based on Table 1).

Once determined the number of cases and given the costs per health indicator, the annual benefits (or avoided external costs) to human health resulting from the implementation of the abatement measures/scenarios were estimated for the study domain using a 1$\mathrm{km}^{2}$ spatial resolution simulation grid.

\section{Results and discussion}

Results are presented for individual measures (HYB, FIR, LEZ and IND), combinations of two measures (HYB + FIR and FIR + IND) and a scenario including all measures (HYB + FIR + LEZ + IND).

The spatial distribution of total health benefits (Fig. 3) shows a strong positive correlation between population density and health benefits (in $€ /$ year) obtained from the assessed reduction scenarios. It means, therefore, that potential health benefits of reduction scenarios are largest in densely populated areas (marked in blue on maps) with high anthropic activity and, thus, where air pollution problems are most alarming. Moreover, these abatement measures are focused on the main activity sources that are mostly concentrated in urban centers and, hence, air quality improvements are more significant in these air pollution hotspots. The largest health benefits from PM10 level improvements are obtained in the Grande Porto municipalities, in particular Porto, Matosinhos, Maia and Vila Nova de Gaia. The exception is the LEZ scenario, whose effects and health benefits are limited to the influence area of the proposed LEZ in Porto.

Considering the entire study domain, a positive linear correlation is observed between the average air quality improvement and the total health benefits for the assessed abatement measures/ scenarios (Fig. 4). This linearity occurs due to simplified arithmetic operation used to calculate the health impacts (Eqn. (2)), keeping the exposed population and the impact functions as spatially constant elements to all scenarios. Fig. 4 clearly shows what reduction scenarios contribute most to air quality improvement in the study domain. Regarding the implementation of individual measures, the industry scenario (IND) is most effective to abate PM10 air pollution levels (average improvement of $0.61 \%$ ) while the Low Emission

Table 2

Input data used for quantifying health impacts and external costs associated with PM10 abatement measures/scenarios.

\begin{tabular}{|c|c|c|c|c|c|c|}
\hline Health effect & Age group & Study design & Relative risk (\%) & Baseline annual rate (\%) & Cost $(€)$ & Unit \\
\hline Asthma & $5-19 \mathrm{yr}$ & Short-term & 0.28 & 17 & 115 & Day \\
\hline Heart failure & $>65 \mathrm{yr}$ & Short-term & $1.85 \mathrm{E}-05$ & Included in RR & 18,538 & Case \\
\hline Chronic bronchitis (incidence) & $>18 \mathrm{yr}$ & Long-term & 1.17 & 0.39 & 18,970 & Year \\
\hline Chronic bronchitis (prevalence) & $6-18 \mathrm{yr}$ & Long-term & 0.8 & 18.6 & 18,970 & Year \\
\hline Total mortality & $<1 \mathrm{yr}$ & Long-term & 0.4 & 0.163 & 1844 & YOLL \\
\hline
\end{tabular}

Note: Costs were updated to the base year (2012). 


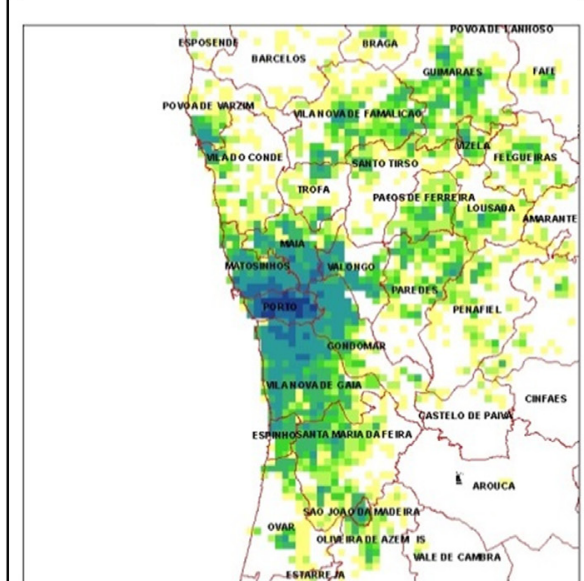

HYB

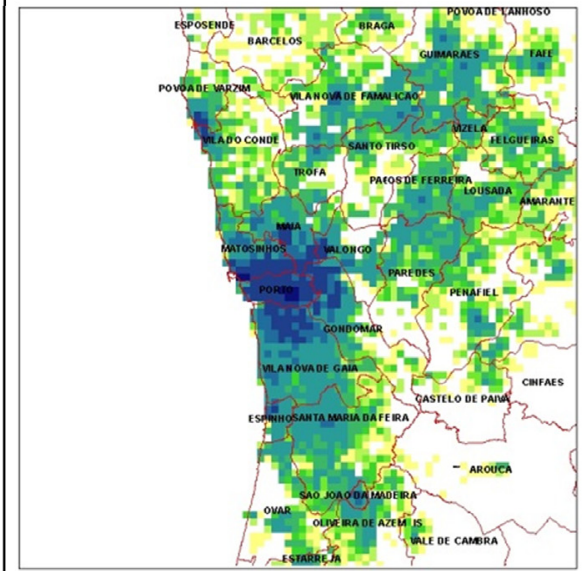

IND

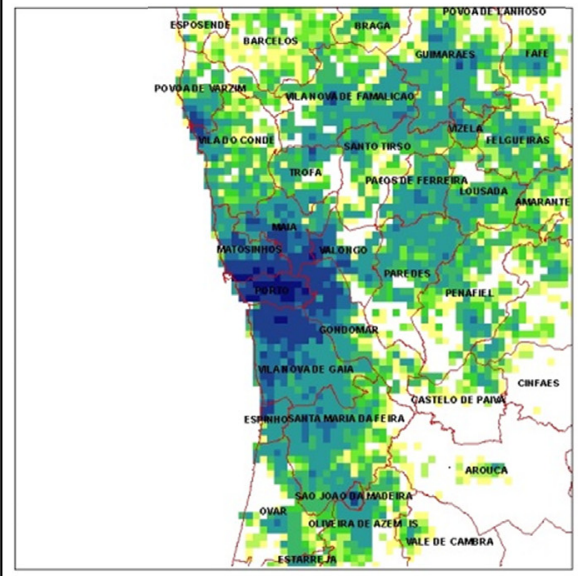

HYB+FIR+LEZ+IND

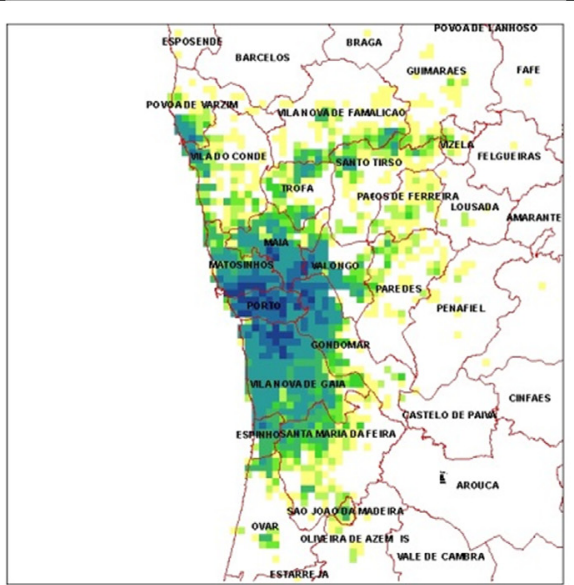

FIR

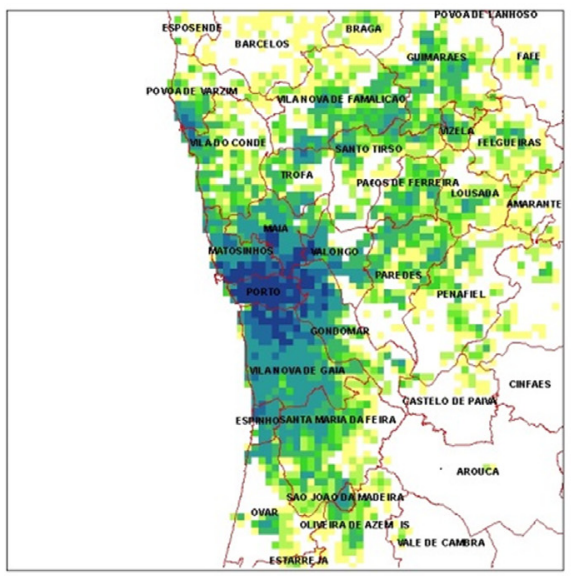

HYB+FIR

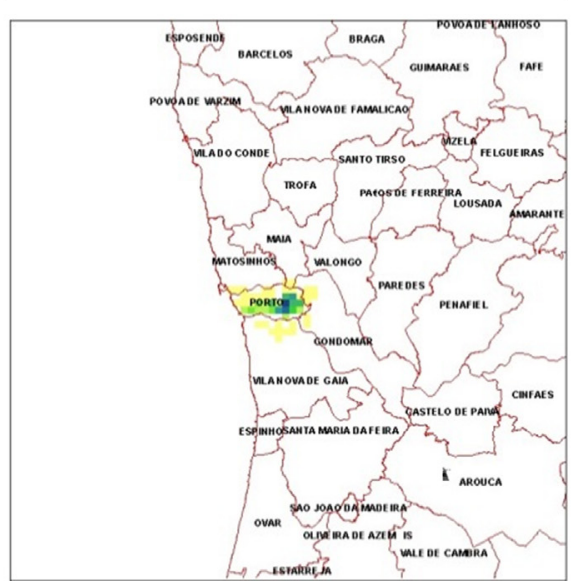

LEZ

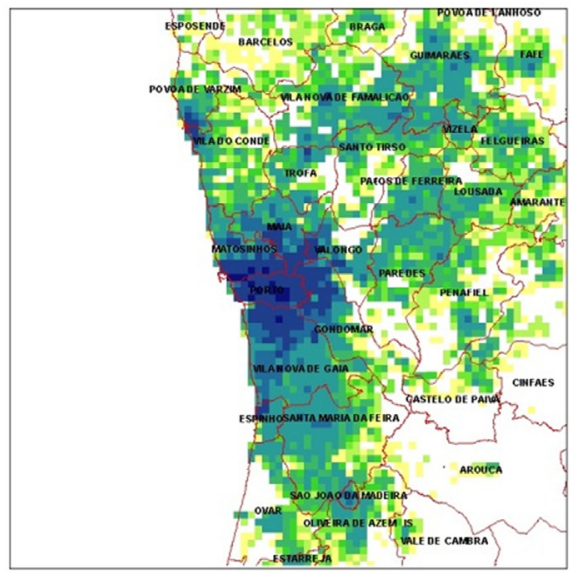

FIR+IND

Legend:

$\square$ Municipalities

\section{Benefit (Euro/yr)}

$100-200$

$200-300$

$-300-400$

$400-500$

$500-1000$

1000 - 5000

- 5000 - 10000

10000 - 50000

50000 - 110000

Fig. 3. Spatial distribution of total health benefits (in $€ / y r$ ) estimated for PM10 abatement measures/scenarios.

Zone scenario (LEZ) is least effective to reduce PM10 concentrations (almost no improvement due to restricted influence area) in the Grande Porto area. The abatement scenario combining all measures $(\mathrm{HYB}+\mathrm{FIR}+\mathrm{LEZ}+\mathrm{IND})$ leads to a reduction in PM10 air pollution of almost $1 \%(0.97 \%)$, corresponding to an expected health benefit of 8.8 million $€ /$ year.

Similarly, albeit slightly less significant, a positive linear correlation is observed between the total PM10 emission reduction and the total health benefits for the assessed abatement measures/ scenarios (Fig. 5). This discrepancy is related to the fact that air quality is not only determined by emissions, but also by the physical and chemical processes involved. Nevertheless, the PM10 emission reduction benefits are closely related to the PM10 air quality improvement benefits for the assessed abatement measures/scenarios - roughly in the ratio of eight to one. Again, the industry scenario (IND) is most effective (reduction of $4.34 \%$ ) while 


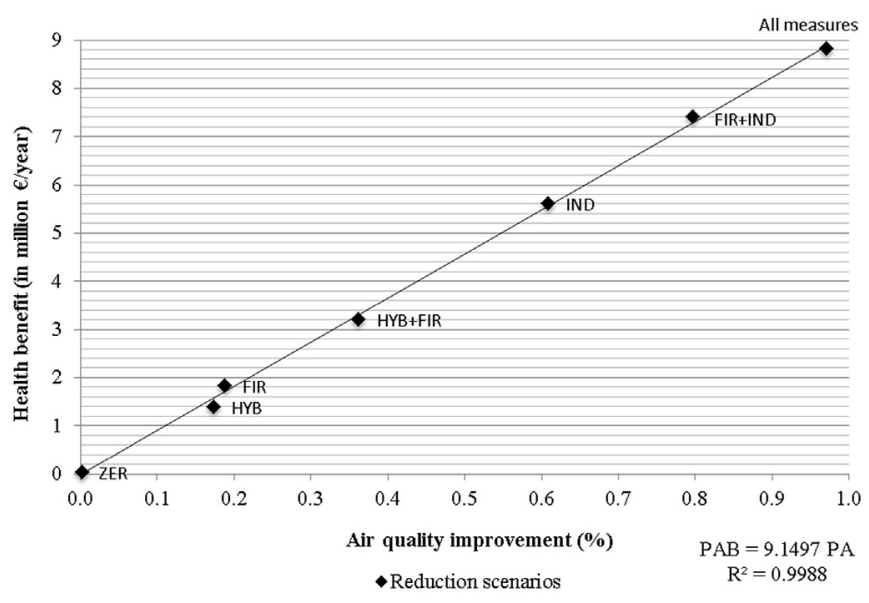

Fig. 4. Air pollution abatement rates ( $P A$; in \% decrease from base) and benefits ( $P A B$; in $\mathrm{m} € / \mathrm{yr}$ ) for PM10 abatement measures/scenarios in Grande Porto.

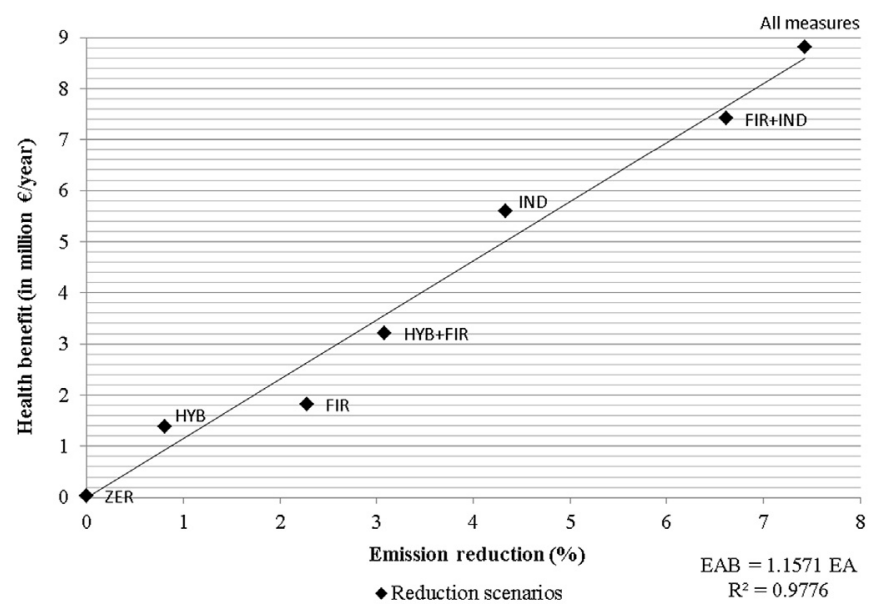

Fig. 5. Emission abatement rates ( $E A$; in \% decrease from base) and benefits ( $E A B$; in $\mathrm{m} € / \mathrm{yr})$ for PM10 abatement measures/scenarios in Grande Porto.

the Low Emission Zone scenario (LEZ) is least effective for the reasons previously mentioned (reduction close to 0\%). For the combined abatement scenario (HYB + FIR + LEZ + IND), a PM10 emission reduction of almost $8 \%$ was estimated (7.42\%) - corresponding to the abovementioned expected health benefit of 8.8 million $€ /$ year.

\section{Conclusions}

In this study the health impacts related to air pollution were addressed, given the growing societal concern associated with alarming levels of air pollution and corresponding cases of mortality and morbidity. Firstly, a review on the available methodologies for the quantification of these impacts and subsequent external costs was carried out and, in turn, the effectiveness and health benefits from emission abatement measures/scenarios were assessed using the Impact Pathway Approach.

Economic evaluation studies on air pollution impacts employ several techniques to estimate the economic costs and benefits resulting from air quality changes. The key issues to estimate health costs derived from air pollution are broadly related with two different concerns: i) how to identify all physical impacts, and ii) how these impacts can be converted in monetary values. Although many studies have been developed to address these issues, none of them is complete given that they omit some measurable cost components and have limitations with respect to the methods used in estimating damage costs. In order to overcome these methodological weaknesses, further research is essential to improve the health impact assessments related with air pollution - contributing to decrease associated uncertainties. The following priority areas are commonly recognized by the scientific community:

- to explore human exposure at the personal level and in different microenvironments;

- to investigate the health impact due to exposure to multiple pollutants (cocktail effect);

- to improve monetary valuation of health impacts through empirical studies that aim to assess the cost elements integrating individual WTP; and

- to improve the coverage of potentially important effects in costbenefit studies of air pollution control programs.

This study is aligned with the last research recommendation, as air quality improvement strategies are proposed to assess health impacts and benefits. Nevertheless, the positive effects of these abatement measures/strategies are often underestimated because there are associated health implications beyond those health indicators here analysed. On the other hand, it is important keeping in mind that the implementation of emission abatement measures/ strategies produces benefic effects on the reduction of multiplepollutant concentrations and, consequently, the benefits extend to other damage categories, such as ecosystems, biodiversity, crops, buildings and materials.

\section{Acknowledgements}

The authors would like to acknowledge the financial support of FEDER through the COMPETE Programme and the national funds from FCT - Science and Technology Portuguese Foundation within project PEst-C/MAR/LA0017/2013 for the MAPLIA Project (PTDC/ AAG-MAA/4077/2012), and also the doc grant of C. Silveira (SFRH/ $\mathrm{BD} / 112343 / 2015$ ) and the post-doc grant of J. Ferreira (SFRH/BPD/ $100346 / 2014)$.

\section{References}

Ballester, F., Rodríguez, P., Iñíguez, C., Saez, M., Daponte, A., Galán, I., Taracido, M., Arribas, F., Bellido, J., Cirarda, F.B., Cañada, A., Guillén, J.J., Guillén-Grima, F., López, E., Pérez-Hoyos, S., Lertxundi, A., Toro, S., 2006. Air pollution and cardiovascular admissions association in Spain: results within the EMECAS project. J. Epidemiol. Commun. Health 60, 328-336.

Belhaj, M., Fridell, E., 2010. External Costs in the Transport Sector: a Literature Review. The Swedish Environmental Research Institute, Stockholm, Sweden.

Borrego, C., Monteiro, A., Sá, E., Carvalho, A., Coelho, D., Dias, D., Miranda, A.I., 2012. Reducing $\mathrm{NO}_{2}$ pollution over urban areas: air quality modelling as a fundamental management tool. Water Air Soil Pollut. 223, 5307-5320.

Brandt, J., Silver, J.D., Christensen, J.H., Andersen, M.S., Bønløkke, J.H., Sigsgaard, T., Geels, C., Gross, A., Hansen, A.B., Hansen, K.M., Hedegaard, G.B., Kaas, E., Frohn, L.M., 2013. Contribution from the ten major emission sectors in Europe and Denmark to the health-cost externalities of air pollution using the EVA model system - an integrated modelling approach. Atmos. Chem. Phys. 13, $7725-7746$.

Carnevale, C., Finzi, G., Pisoni, E., Volta, M., Guariso, G., Gianfreda, R., Maffeis, G., Thunis, P., White, L., Triacchini, G., 2012. An integrated assessment tool to define effective air quality policies at regional scale. Environ. Model. Softw. 38, 306-315.

Costa, S., Ferreira, J., Silveira, C., Costa, C., Lopes, D., Relvas, H., Borrego, C., Roebeling, P., Miranda, A.I., Teixeira, J.P., 2014. Integrating health on air quality assessment-review report on health risks of two major European outdoor air pollutants: PM and $\mathrm{NO}_{2}$. J. Toxicol. Environ. Health Part B Critical Rev. 17 (6), 307-340.

DEFRA (Department for Environment, Food and Rural Affairs), 2013. Impact Pathway Guidance for Valuing Changes in Air Quality. London, UK, 20 pp.

DEFRA (Department for Environment, Food and Rural Affairs), 2004. Valuation of 
the External Costs and Benefits to Health and Environment of Waste Management Options, Final Report for DEFRA by Enviros Consulting Limited in Association with EFTEC (London, UK).

EC (European Commission), 2008. Directive 2008/50/EC of the European parliament and of the council of 21 May 2008 on ambient air quality and cleaner air for Europe. Off. J. Eur. Union L152.

EC (European Commission), 2005. In: Bickel, Peter, Friedrich, Rainer (Eds.), ExternE Externalities of Energy - Methodology 2005 Update. Office for Official Publications of the European Communities. EUR 21951 EN.

EHA (Environment and Health Administration), 2006. The Stockholm Trial: Effects on Air Quality and Health. Report SLB 4:2006, Stockholm, 62 pp.

Hammitt, J.K., 2007. Methodological Review of WTP and QALY Frameworks for Valuing Environmental Health Risks to Children, Report Prepared for the OECD Project on the "Valuation of Environment-related Health Impacts, with a Particular Focus on Children". Harvard University, USA.

Hanly, P., Timmons, A., Walsh, P.M., Sharp, L., 2012. Breast and prostate Cancer productivity costs: a comparison of the human capital approach and the friction cost approach. Value Health 15, 429-436.

Holland, M., Hunt, A., Hurley, F., Navrud, S., Watkiss, P., 2005. Methodology for the Cost-benefit Analysis for CAFE - Volume 1: Overview of Methodology. AEA Technology Environment, Didcot, UK.

Hurley, F., Hunt, A., Cowie, H., Holland, M., Miller, B., Pye, S., Watkiss, P., 2005a. Methodology for the Cost-benefit Analysis for CAFE - Volume 2: Health Impact Assessment. AEA Technology Environment, Didcot, UK.

Hurley, P., Physick, W., Luhar, K., 2005b. TAPM: a practical approach to prognostic meteorological and air pollution modelling. Environ. Model. Softw. 20, $737-752$.

International Institute for Applied Systems Analysis, 2012. The Greenhouse Gas and Air PollutInternational Instituteion Interactions and Synergies (GAINS) -Model. Laxenburg, Austria. http://gains.iiasa.ac.at/models/.

Koopmanschap, M.A., van Ineveld, B.M., 1992. Towards a new approach for estimating indirect costs of disease. Soc. Sci. Med. 34 (9), 1005-1010.

Maibach, M., Schreyer, C., Sutter, D., van Essen, H.P., Boon, B.H., Smokers, R., Schroten, A. Doll, C. Pawlowska, B., Bak, M., 2008. Handbook on Estimation of External Costs in the Transport Sector, Report Produced within the Study Internalisation Measures and Policies for All External Cost of Transport (IMPACT), Version 1.1, CE Delft, 332 pp.

Marques, R.C., Cruz, N.F., Simões, P., Ferreira, S.F., Pereira, M.C., 2013. EIMPack Economic Impact of the Packaging and Packaging Waste Directive, Task 5 Environmental Valuation (Literature Rieview), Work Programme Financed by European Investment Bank. Instituto Superior Técnico, Lisbon, Portugal, 57 pp.

Mechler, R., Amann, M., Schöpp, W., 2002. A Methodology to Estimate Changes in Statistical Life Expectancy Due to the Control of Particulate Matter Air Pollution, Interim Report IR-02-035 on Work of the IIASA. Laxenburg, Austria, $41 \mathrm{pp}$.

Miranda, A.I., Silveira, C., Ferreira, J., Monteiro, A., Lopes, D., Relvas, H., Borrego, C., Roebeling, P., 2015. Current air quality plans in Europe designed to support air quality management policies. Atmos. Pollut. Res. 6, 434-443. http://dx.doi.org/ 10.5094/APR.2015.048.
Pervin, T., Gerdtham, Ulf-G., Lyttkens, C.H., 2008. Societal costs of air pollutionrelated health hazards: a review of methods and results. Cost Eff. Resour. Allocation 6 (19), 22 pp.

Pizzol, M., Smart, J.C.R., Thomsen, M., 2014. External costs of cadmium emissions to soil: a drawback of phosphorus fertilizers. J. Clean. Prod. 84, 475-483.

Pizzol, M., Thomsen, M., Frohn, L.M., Andersen, M.S., 2010. External costs of atmospheric $\mathrm{Pb}$ emissions: valuation of neurotoxic impacts due to inhalation. Environ. Health 9 (9), 9.

Roebeling, P.C., Van Grieken, M.E., Webster, A.J., Biggs, J.S., Thorburn, P., 2009. Costeffective water quality improvement in linked terrestrial and marine ecosystems: a spatial environmental-economic modelling approach. Mar. Freshw. Res. $60,1150-1158$

Ruckerl, R., Schneider, A., Breitner, S., Cyrys, J., Peters, A., 2011. Health effects of particulate air pollution: a review of epidemiological evidence. Inhal. Toxicol. 23, 555-592.

Seethaler, R.K., Künzli, N., Sommer, H., Chanel, O., Herry, M., Masson, S., Vernaud, J.C., Filliger, P., Horak Jr., F., Kaiser, R., Medina, S., Puybonnieux-Texier, V. Quénel, P., Schneider, J., Studnicka, M., Heldstab, J., 2003. Economic costs of air pollution-related health impacts: an impact assessment project of Austria, France and Switzerland. Clean Air Environ. Qual. 37 (1), 35-43.

Seethaler, R., 1999. Health Costs Due to Road Traffic-related Air Pollution: an Impact Assessment Project of Austria, France and Switzerland. Synthesis Report published by Federal Department of Environment, Transport, Energy and Communications, Berne, Switzerland, 105 pp.

Silveira, C., Lopes, M., Roebeling, P., Ferreira, J., Costa, S., Teixeira, J.P., Borrego, C., Miranda, A.I., 2015. Economic evaluation of air pollution impacts on human health: an overview of applied methodologies. In: The 23rd International Conference on "Modelling, Monitoring and Management of Air Pollution", 1-3 June, Valencia, Spain, Air Pollution XXIII Conference Proceedings, pp. 181-192.

Tranmer, J.E., Guerriere, D.N., Ungar, W.J., Coyte, P.C., 2005. Valuing patient and caregiver time: a review of the literature. Pharmacoeconomics 23 (5), 449-459.

van Essen, H., Schroten, A., Otten, M., Sutter, D., Schreyer, C., Zandonella, R. Maibach, M., Doll, C., 2011. External Costs of Transport in Europe, Update Study for 2008. CE Delft, Netherlands.

Wang, X., Mauzerall, D.L., 2006. Evaluating impacts of air pollution in China on public health: implications for future air pollution and energy policies. Atmos. Environ. 40, 1706-1721.

WHO (World Health Organization), 2013a. Health Effects of Particulate Matter: Policy Implications for Countries in Eastern Europe, Caucasus and Central Asia. WHO Regional Office for Europe, Geneva, 20 pp.

WHO (World Health Organization), 2013b. Recommendations for Concentration-response Functions for Cost-benefit Analysis of Particulate Matter Ozone and Nitrogen Dioxide, Health Risks of Air Pollution in Europe - HRAPIE Project. WHO Regional Office for Europe, Copenhagen, Denmark, 54 pp.

WHO (World Health Organization), 2008. Economic Valuation of Transport-related Health Effects: Review of Methods and Development of Practical Approaches, with a Special Focus on Children. WHO Regional Office for Europe, Copenhagen, Denmark. 